\title{
From Individuals to Organizations: The Puzzle of Organizational Liability in Tort Law
}

\author{
Klaus Heine \& Kateryna Grabovets*
}

\section{Introduction}

Daily routine teaches us that organizational structure matters when mistakes and accidents take place in organizations. ${ }^{1}$ For example, the safe operation of a train does depend not only on the skills of the engine driver but also on the proper organization of the railway company. This leads to the question whether it is possible to identify the organizational attributes that properly reflect the risk of accidents. And if such attributes can be identified, what are the legal consequences? Can liability rules and legal standards of care effectively address the organizational factors of accident occurrence and induce precautions at the organizational level?

These are very topical questions. A striking example is the fatal Washington metro crash of 22 June 2009. The crash made it apparent that organizational deficiencies led to the systemic breakdown of safety management at all levels. ${ }^{2}$ According to a member of the National Transportation Safety Board (NTSB), the volume of alarms incorrectly detecting the location of trains was very high. But this technical problem was ignored persistently at all levels of the organization. Another NTSB member stated that "this accident was a classic example of an organizational accident", blaming the metro's employees, managers and board, as well as the designers and manufacturers of the train-control system. In the aftermath of the accident, the safety regulations for transit systems became tighter. ${ }^{3}$ But is more regulation the only answer to the mentioned problems? ${ }^{4}$ Can tort law adequately address these problems?

In this article we ask whether it is possible to expand the scope of the economic analysis of tort law by incorporat-

Prof. Dr. Klaus Heine (Corresponding author), Jean Monnet Chair of Economic Analysis of European Law, Erasmus School of Law - RILE, Erasmus University Rotterdam, Burgemeester Oudlaan 50, Room J6-59, Postbus 1738, NL-3000 DR Rotterdam, The Netherlands. Tel: 0031 (0)10 4082691; Fax: 0031 (0)10 4089191. Dr. Kateryna Grabovets, Rotterdam Business School (RBS), Rotterdam University of Applied Sciences, Kralingse Zoom 91, Room C3.121, 3063 ND Rotterdam; P.O. Box 25035, 3001 HA Rotterdam, The Netherlands. Tel: 0031 (0)10 7946243. k.a.grabovets@hr.nl

\section{Perrow 1981, 1999; for an overview see Vaughan 1999.}

'Fatal Washington' 2010.

Ibid.

Ford \& Condon 2011. ing insights from organizational science. To this end, we provide a simple organizational design framework.

The article proceeds with a brief overview of organizational wrongdoing from the perspective of economic analysis of tort law (2). It will be shown that economic analysis of tort liability is predominantly based on agency theory and thus aimed at optimizing incentives. We then claim that insights from organizational science are widely neglected in the economic analysis of organizational liability (3). We analyze some root causes of organizational wrongdoing, highlighting the incompleteness of the agency approach, and subsequently we stress the relevance of other organizational characteristics, such as organizational culture, complexity, coordination of organizational activities and organizational design. Finally, in (4), we depart from the conceptual observations. We come up with an organizational framework based on the approach of Sah and Stiglitz ${ }^{5}$ on organizational architectures. We argue that a smart design of organizational layers, enforced by tort law, is essential for reducing wrongdoing and increasing welfare.

\section{Organizational Liability through the Lenses of Law and Economics: A Critical Look}

Usually liability of one person cannot be imputed to another person. However, according to the common law concept of vicarious liability, a master can be held liable for a negligent act of his agent. These master-servant relationships are typically found between parents and children, employers and employees or contractors and subcontractors. ${ }^{6}$ For example, if a driver of a milk delivery truck is found negligent for an accident, then the dairy factory that employed the driver bears liability and pays damages. ${ }^{7}$ However, it is not enough to refer to legal doctrines in an attempt to determine why an organization should be liable if misconduct is in essence a result of human actions and decisions.

\footnotetext{
Sah \& Stiglitz 1985b, 1986.

Shavell 2007, p. 171.

West's Encyclopedia of American Law 2003.
} 
The economic analysis of law provides an analytical answer to this question and undertakes two consecutive steps in doing so. While the first step is the positive economic analysis of the relationship between an organization and individual wrongdoing, the second step is the provision of normative suggestions for a proper design of tort liability.

If it is assumed that wrongdoing results from the actions or decisions of individuals, then the imposition of organizational liability can be explained by the principal-agent framework. That is, the agent (the individual) commits wrongdoing when he is improperly controlled or inadequately incentivized by the principal (the organization). From this perspective, organizational wrongdoing is the result of a flawed agency setting, in which agents receive insufficient incentives from the principal to behave with a due level of care. ${ }^{8}$ Thus, wrongdoing, either it is intentional or not, is the fault of the principal, even if wrongdoing is not authorized by the latter. Therefore, liability is imposed on the organization.

From a normative point of view, the lawmaker should choose a liability rule that induces the principal to properly control and incentivize the agent. Accordingly, the common law doctrine of vicarious liability corresponds to the need of creating optimal incentives in the principal-agent setting. Vicarious liability makes an organization strictly liable for wrongdoings of its employees. ${ }^{9}$

The underlying economic idea of vicarious liability is that organizations have to internalize all inflicted costs, including the costs of accidents caused by organizational activities. It is assumed that organizations rationally respond to tort law incentives and choose optimal precautions, as well as the optimal activity level. ${ }^{10}$ As a result, it is expected that the sold products and services are appropriately priced and hence a socially optimal amount of goods and services is attained. ${ }^{11}$ Apart from being held strictly liable, organizations may also be liable for accidents committed by their employees based on negligence. Under the so-called negligence rule, organizations bear liability only if their agents exercised less than reasonable care. ${ }^{12}$

However, irrespective of the type of liability (strict or negligence), an important criticism of organizational liability based on agency relationships is that it may prevent the establishment of internal corporate compliance structures which induce employees to exercise optimal precautions. Organizations may be reluctant to establish proper internal compliance structures because these structures make wrongful behaviour easier to detect and thus may increase the compensation amounts paid to victims. ${ }^{13}$ According to Arlen and MacLeod, "vicarious liability discourages the efficient exercise of control because organizations which exert control over agents

8. Sykes 1984, 1988; Arlen \& Kraakman 1997; Kraakman 2009.

9. DeMott 1997, p. 40; Sykes 1984.

10. Shavell 1980

11. See, Shavell 2007, p. 156; Sykes 1984. For an extension to corporate crime, see Fischel \& Sykes 1996.

12. Henderson 2002, p. 380.

13. Arlen 1994; Krawiec 2005 are likely to be deemed 'masters', and thus face liability for their agents' torts". ${ }^{14}$ In other words, organizational liability may create perverse incentives that discourage organizations from implementing adequate compliance structures. $^{15}$

Thus, organizational tort liability should provide incentives that go beyond narrow agency relationships. It should also take root causes of organizational accidents into account, such as organizational structure and organizational culture. For example, describing medical malpractice in Poland, Heiderhoff and $\mathrm{Zmij}$ mention that "for the purpose of ascribing the [organizational] guilt, particular standards of correct conduct of a team or structure should be determined". ${ }^{16}$ The authors also mention that in medical malpractice and particularly in the case of hospital infections, the wrongful conduct of medical staff can be related to a "malfunction of a particular organizational structure". ${ }^{17}$

It is worth noting that, in criminal law, organizational (corporate) standards of care play a more visible role than in tort law. ${ }^{18}$ In criminal law, a broader perspective on wrongdoing has already been established. ${ }^{19}$ For example, Baysinger and Krawiec provide a detailed discussion of the Federal Organizational Sentencing Guidelines from an organizational perspective. ${ }^{20}$ Moreover, Foerschler claims forcefully that "to develop an accurate paradigm with which to assess corporate criminal liability, the law should look to organization theory". ${ }^{21}$ In tort law, however, insights from organizational science have been widely neglected. The academic debate remains focused on individual negligence, with agency theory used as the dominant analytical tool. One could even go further, arguing that law and economics transform the economic fiction of an individual decision maker into the legal fiction of an organization that consists of independent decision makers ('atomistic contracting'). ${ }^{22}$ Consequently, the scope of existing organizational liability regimes is rather limited. They aim at ensuring better monitoring and providing better incentives to single agents. Yet, root causes of organizational wrongdoing are not addressed directly. ${ }^{23}$ Pointing to this narrow approach, Mello and Studdert note that, "tort incentives run to individuals, not organizations". ${ }^{24}$ Moreover, as can be seen from the inferences drawn by Shavell, ${ }^{25}$ in the law and economics literature there is no distinction made between the liability effects on individuals and organizations.

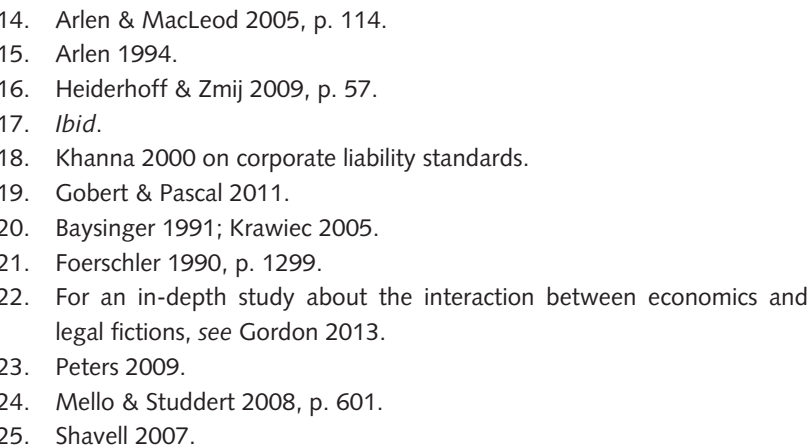


The way that liability rules function [when injurers are firms] is similar to how they function when injurers are individuals; the effect of liability on firms' care is the same as on individual injurers' care. ${ }^{26}$

Therefore, some authors critically observe that firms become anthropomorphized in the economic analysis of tort law. ${ }^{27}$

The following sections provide a more detailed look on organizational science and its contribution to a more comprehensive analysis of organizational liability.

\section{Organizational Wrongdoing from an Organizational Science Perspective}

\subsection{Antecedents of Organizational Wrongdoing}

From the perspective of organizational science, contemporary liability rules for organizational wrongdoing reflect a one-dimensional solution. They simply translate an organizational failure into an agency problem. The underlying idea is that principals and agents are rational utility maximizers who adequately react to incentives. ${ }^{28}$ Thereby the insights from organizational science are largely neglected. This lacuna implies that one should seek for a more composite approach towards organizational wrongdoing. However, this is not an easy task to accomplish. Punch puts it to the point:

This conceptual perspective does not sit easily with the law and with many lawyers, as both tend to be rooted in a rather narrow individualism; but also not with those social scientists and philosophers who would argue that organizations do not exist outside of the perceptions and actions of individuals. ${ }^{29}$

A promising starting point towards a more integrated perspective on organizational wrongdoing is to take the interrelation between external factors and internal organizational characteristics seriously. For example, Baucus and Near spot several categories of antecedents that may trigger wrongful behaviour in organizations. ${ }^{30}$ They distinguish environmental antecedents of wrongdoing, such as scarcity of resources, dynamism of organizational changes in response to changes in the environment and heterogeneity of the environment in which a company operates. The authors also identify that a company's performance and size belong to internal antecedents of wrongdoing. Clinard and Yeager examine causal factors of corporate crime, distinguishing between internal structure and external factors. ${ }^{31}$ In particular,

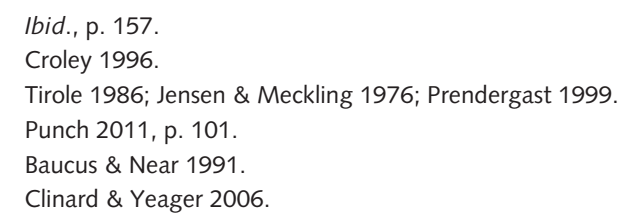

they emphasize the role of organizational complexity in the emergence of wrongdoing. They draw a picture, in which poor economic performance of an organization, delegated authority, managerial discretion, a lack of responsibility of top managers as well as corporate culture and corporate ethical standards are so heavily intertwined that such complexity generates organizational wrongdoing. Thus, organizational wrongdoing occurs not only because of deliberate (rational) decision-making of individuals, but it is highly contingent on other variables as well, which is an important inference for law and economics.

Since our aim is not to review the whole range of possible triggers of wrongdoing that could be drawn from organizational science literature, we limit our focus to two important factors of wrongdoing: (1) behavioural triggers and organizational culture and (2) organizational complexity and coordination. ${ }^{32} \mathrm{We}$ analyze these categories because they clearly illustrate the drawbacks of neglecting the organizational context. Moreover, the focus on these categories allows us to take the incremental steps towards expanding the theoretical base of tort law analysis and employ relevant insights from organizational science for the improvement of tort liability.

\subsection{Behavioural Triggers and Organizational Culture}

From an agency perspective, potential wrongdoers, namely employees, exploit information asymmetries between a principal and an agent. Agents calculate expected costs and benefits of wrongdoing. If the calculation brings a positive payoff for them, the agents will exert a low level of care, making wrongdoings more likely to occur. But this rationale cannot easily explain why employees quite often become involved in wrongdoing which benefits the organization, but not the individual wrongdoer. ${ }^{33}$

Even though it can be argued that an employee expects some private benefits from wrongdoing, such as promotion within a company, it is nevertheless questionable that the expected individual benefits from the negligent behaviour outweigh the incurred costs. This raises the question of behavioural triggers underlying such a behaviour. For example, a wrong risk perception can be an important trigger for wrongdoing. ${ }^{34}$ An individual may systematically underestimate risks and thereby increase the likelihood of failure. ${ }^{35}$ Moreover, individuals may falsely rely on the expertise of others who underestimate risks. ${ }^{36}$ For example, this misperception plays out with regard to excessive reliance of investors on credit rating agencies. ${ }^{37}$ The recent financial crisis provides even more examples of decisions made on the basis of misleading information. However, cognitive

32. For an overview of various organizational factors of wrongdoing, see Clinard \& Yeager 1980, 2006; Payne 2013; McKendall, DeMarr \& Jones-Rikkers 2002; Simpson, Piquero \& Paternoster 2012.

33. Krawiec 2000.

34. Slovic 2000; Vaughan 1982, 1999.

35. Koellinger, Minniti \& Schade 2007; Moore \& Kim 2003

36. Bonaccio \& Dalal 2006; James 2000.

37. Amtenbrink \& Heine 2013. 
limitations alone cannot fully explain wrongdoing in organizations.

To better explain wrongdoing, organizational factors have to be taken into account. ${ }^{38}$ One decisive factor is organizational culture. If management positions are systematically filled with individuals who have a high propensity for risk taking, the likelihood of wrongdoing in an organization increases. In this respect, March and Shapira have pointed out that:

although [managers] undoubtedly vary in their individual propensities to take risks, those variations are obscured by processes of selection that reduce the heterogeneity among managers and encourage them to believe in their ability to control the odds. ${ }^{39}$

Indeed, organizational culture and management practices, as well as the business environment in which an organization is embedded, have an impact on the likelihood of wrongdoing. ${ }^{40}$ Those factors can thus lead to dangerous shifts in risk taking. This can be illustrated by the example of some oil and gas companies. British Petroleum (BP) is characterized by excessive cost cutting and excessive risk taking with respect to environmental issues and worker safety. ${ }^{41}$ In contrast to BP, ExxonMobil is acknowledged to have a better performance in terms of environmental and worker safety. ${ }^{42}$ According to ExxonMobil's CEO, Rex Tillerson, “companies must develop a culture in which the value of safety is embedded in every level of the workforce, reinforced at every turn and upheld above all other considerations". ${ }^{43}$ Although one may qualify the official statements of a company as cosmetic or window-dressing, it nevertheless points to the fact that there are obviously distinct features in otherwise similar firms. These features can make a decisive impact on the likelihood of wrongdoing.

The implied question, why some companies are more prone to wrongdoings than others, can partly be explained by imprinting theory. ${ }^{44}$ In a nutshell this theory states that early organizational configurations have a lasting imprint on future organizational behaviour. For example, if at its founding stage an organization tolerates wrongdoing, then this attitude will not only be an episode but will be transformed in a consistent pattern when the organization becomes mature. More precisely, one might assume that superiors sufficiently monitor subordinated employees in order to prevent wrongdoing, simply because they are supposed to monitor subordinates. But this is not necessarily the case because superiors have often the same imprint ${ }^{45}$ and the same morale and attitude as juniors. ${ }^{46}$ Juniors

38. Langevoort 1997, 2006; Vaughan 1999.

39. March \& Shapira 1987, p. 1414.

40. Brodie 2007, p. 494; Ford \& Hess 2011

41. Shefrin \& Cervellati 2011

42. Pulver 2007, pp. 68-69.

43. Mannan, Mentzer \& Zhang 2013, p. 1424.

44. Stinchcombe 1965.

45. Ibid.

46. Punch 2011, pp. 101-102 are imprinted by seniors, who were juniors in the past; thus, behavioural patterns become inherited. This may prevent effective monitoring and leads to relaxed standards of safety in a company over time. This can be further illustrated by corporate culture in investment banking, where superiors may perceive that their primary obligation is not supervision but the exploitation of the firm's profit opportunities. ${ }^{47}$ For example, employees of Prudential Financial, Inc., were charged for securities fraud in 2003. In court, the traders claimed that the compliance department, risk managers and high-level executives knew of the fraudulent trades and rewarded traders for the profit they earned for the company (Securities and Exchange Commission v. Druffner et al. ${ }^{48}$ ).

Another example that demonstrates that imprinting significantly impacts the relationships between superiors and subordinates is the Australian mining industry. Low-level managers, the so-called deputies, at the mine sites are chosen from the rank of workers, and they are concerned about maintaining their "ties of 'mateship' with the crews". ${ }^{49}$ Moreover, deputies predominantly work among other workers and are largely detached from the rest of the management. ${ }^{50}$ The strong ties within the workforce prevent effective monitoring and put the monitoring of safety standards at risk.

In summary, it turns out that organizational culture and behavioural triggers are decisive factors of negligence and wrongdoing. One can conjecture that tort liability rules which target solely the rational behaviour of individuals are not well-equipped to tackle wrongdoing in organizations. A similar conclusion can be drawn from taking into consideration organizational complexity and coordination, which are discussed in the following section.

\subsection{Organizational Complexity and Coordination}

While in management organizational complexity is a prominent field of research for many decades, it has virtually gained no attention in the economic analysis of law. Only the literature on corporate crime makes an exception, emphasizing that a high degree of organizational complexity is associated with a higher probability of illegal behaviour. It is argued that organizational complexity leads to fragmented communication, difficulties in coordination and less managerial control. ${ }^{51}$ Those problems also give leeway to commit illegal acts.

Although the provided arguments and observations are made with respect to corporate crime, they are also applicable to organizational wrongdoing in tort law because the problems that stem from complexity point to a more general problem of coordination of organizational activities. Insofar as wrongdoing may not necessarily be caused by a perpetrator (as investigated in the

47. Krawiec 2005.

48. 353 F. Supp. 2d 141 (2005), United States District Court, D. Massachusetts; Barboza 2003, p. C1; Krawiec 2005, p. 601.

49. Gunningham \& Sinclair 2009, p. 878

50. Ibid.

51. McKendall \& Wagner 1997; Finney \& Lesieur 1982. 
corporate crime literature), it may result from the simple fact that certain organizational structures cannot effectively deal with complexity. That is, coordination of activities within an organization may fail, paving the way to unintended wrongdoing, without any deliberate acts or decisions. To give an example, over the last four decades the health care provision has radically transformed from a 'cottage industry', in which individual physicians played a leading role, to a large sector in which hospitals have become the key providers. ${ }^{52} \mathrm{~A}$ hospital's performance significantly depends on the vertical and horizontal organization of medical services and coordination between departments. The cardiology department has to coordinate its activities with the radiography department, the surgery department and many others. Effective coordination will inevitably need vertical oversight to align the services of the different departments. ${ }^{53}$

Various tort law rules impose liability on hospitals, including most prominently vicarious liability. The imposition of vicarious liability on hospitals depends on the presence of the agency relationships between a hospital and physicians. Since employment contracts prove the existence of those relationships, hospitals may avoid direct employment of physicians in order to prevent the imposition of vicarious liability. Indeed, many scholars and medical practitioners observe that the US hospitals are reluctant to have direct employment contracts with physicians. Instead hospitals tend to hire independent contractors, which then 'send out' physicians to hospitals. ${ }^{54}$ The drawbacks of this 'contracting around' practice are impaired organizational coordination, increased complexity and thus a higher risk of malpractice. Similar observations apply to other industries, such as the chemical industry, where the threat of liability is also found to cause adverse effects. ${ }^{55}$

Neither strict organizational liability nor negligencebased liability can effectively cope with wrongdoings, if they are triggered by structural organizational complexity and coordination problems. On the contrary, as the examples from medical malpractice and other sectors illustrate, liability rules may even trigger coordination failures. This leads to wrongdoing that could otherwise be avoided.

Thus, the phenomenon of organizational wrongdoing cannot be fully explained by focusing only on the rational individual. To a large extent, the individual behaviour is shaped and constrained by organizations. Moreover, the agency setting focused on the provision of optimal incentives appears to be a limited framework, as broader

52. Jacobsen \& Pomfret 1999, p. 813; Nathanson 1993

53. Fenn, Gray \& Rickman 2004, p. 278; Stieglitz \& Heine 2007.

54. Abraham \& Weiler 1994; Cebul et al. 2008; Arlen \& MacLeod 2005; Andrews 2005, p. 380; Thornton 2010, p. 313. In the case of independent contractors, hospitals can be vicariously liable on the basis of the doctrine of apparent authority. However, it may be difficult to prove in court that a patient relied on the belief that an independent contractor was a hospital's agent, which is necessary for holding a hospital liable based on the apparent authority doctrine (Peters \& Peraino 1984, p. 254).

55. Rosenthal 1997. coordination failures cannot directly be addressed within it. Therefore, the traditional law and economics criteria for assessing the optimality of liability rules, which is applicable to individual tortfeasors and rational agents, cannot simply be replicated on the level of organizations. To adequately address and analyze these problems at a theoretical level, the current framework of economic analysis of tort law has to be refined. In the following section we further elaborate this idea.

\section{Structural Remedies against Organizational Wrongdoing}

\subsection{Organizational Design and the Propensity for Mistakes}

When organizational factors are identified as distinct triggers of wrongdoing, liability should adequately address those factors and a court has to evaluate whether a company has appropriately organized its activities. This leads to the following question: which organizational arrangements are effective in the prevention of wrongdoing? To answer this question, one has to find out whether it is possible to derive some general insights about the relationship between organizational attributes and the prevention of wrongdoing.

Despite the fact that extensive literature exists on various organizational characteristics, yet there is only scarce knowledge about the relations between organizational factors and the occurrence of wrongdoing. In order to shed more light on this issue, it is promising to employ the approach that is proposed by Sah and Stiglitz on hierarchies and polyarchies. ${ }^{56}$ This approach provides some answers on the effects of organizational design on the occurrence of individual mistakes.

Surely, in order to better understand wrongdoing in organizations, various organizational theories could be used. For example, neoclassical and behavioural approaches could be distinguished, and it could be debated which approach has more explanatory power with respect to organizational wrongdoing. ${ }^{57}$ The advantage of Sah and Stiglitz' approach to organizational design is that it does not make specific assumptions about individuals, thereby avoiding tedious debates over human rationality. The only assumptions made by Sah and Stiglitz are that (1) individuals can make wrong decisions and (2) organizational design is a way to cope with this problem. ${ }^{58}$

Although the Sah and Stiglitz model focuses only on two generic types of organizational design (polyarchy and hierarchy), it nevertheless serves as a promising starting point and an analytical platform for expanding the existing agency framework in the economic analysis of tort law.

\footnotetext{
56. Sah \& Stiglitz 1985b, 1986.

57. For an overview, see McKelvey 1997

58. See also Simon 1979
} 


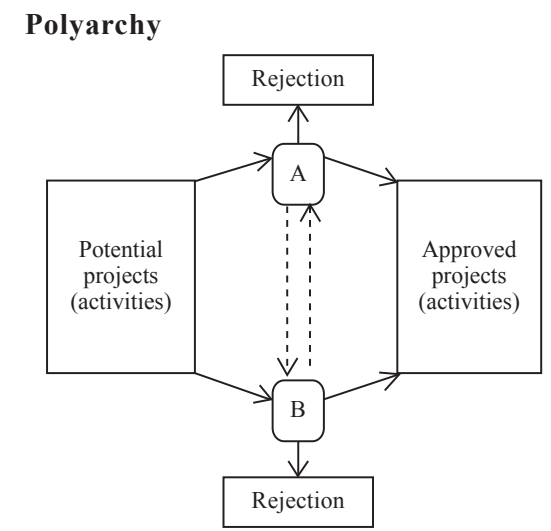

The focus on organizational architectures allows to examine whether it is possible to minimize false human decisions through a resourceful combination of organizational layers. ${ }^{59}$ The core idea is that in a hierarchical organization, an activity can only be realized if all organizational layers have approved it. It is intuitively clear that the likelihood of approval is quite low in such a setting because it must go through multiple hierarchical filters, each of which has to approve an activity. Thus, while rejecting many hazardous activities, a hierarchical organizational design also rejects many harmless activities. Rejection of harmless activities is one of the limitations of the hierarchy. In contrast, a polyarchical organizational design ensures decentralized decision-making. The polyarchy consists of several organizational layers which can approve a project independently from each other. Thus, decentralized polyarchical organization is more likely to approve wrongful activities, but its advantage is that it accepts more harmless activities than a hierarchical design. ${ }^{60}$

The main features of the two generic types of organizational design are depicted in Figure $1 .{ }^{61}$ Assume that an organization consists of organizational units $\mathrm{A}$ and $\mathrm{B}$, each of which can approve a project $\mathrm{P}$ with the probability of 50 percent. Then, the polyarchy approves the project with the probability of 75 percent $(\mathrm{P}(\mathrm{A})$ or $\mathrm{P}(\mathrm{B})$ ), while the hierarchy approves it with the probability of 25 percent $(\mathrm{P}(\mathrm{A})$ and $\mathrm{P}(\mathrm{B})) .{ }^{62}$ Consequently, the polyarchy makes less errors of the 'missed opportunity' nature (Type I errors, or omission errors) than the hierarchy, but simultaneously commits more errors of the 'bad investment' nature (Type II errors, or commission errors) than the hierarchy. The reverse applies to the hierarchy. The hierarchy rejects more projects which should have been accepted. ${ }^{63}$ Thus, hierarchies and pol-

59. An extended analysis of this approach is provided by Christensen \& Knudsen 2010; Koh 1992, 1994; Sah 1991.

60. Sah \& Stiglitz 1986.

61. Sah \& Stiglitz 1986, p. 718; Wu 2006.

62. Probability of approving a project in a polyarchy: $\rho^{\text {Polyarchy }}=50 \%+(1-1 / 2) \cdot 50 \%=75 \%$.

Probability of approving a project in a hierarchy:

$\rho^{\text {Hierarchy }}=50 \% \cdot 50 \%=25 \%$.

63. Sah \& Stiglitz 1985b, 1986; Wu 2006.
Hierarchy

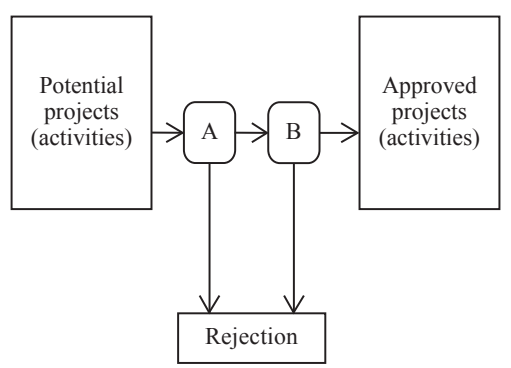

yarchies are committed to different types of failures. This allows for a purposeful filtering of information by combining hierarchical and decentralized organizational layers. ${ }^{64}$ Accordingly, it is possible to design organizations with multiple structural layers which optimally filter information ${ }^{65}$ and lead to the optimal amount of wrongdoing. However, a multiplicity of organizational layers slows down the decision-making process, incurs high transaction costs and increases complexity. ${ }^{66}$ In addition, multiple organizational layers are likely to cause communication errors. Information may be lost or its meaning may get changed. Therefore, in reality it is not simple to determine the efficient organizational structure. However, a basic taxonomy of different organizational designs unfolds in the following section. It may provide a useful framework for defining whether a specific organizational design adequately corresponds to the risk of performed activity. It goes without saying that the proposed taxonomy is only a first step towards more elaborated applications.

\subsection{A Taxonomy of Organizational Design Standards}

From a welfare perspective, it is necessary to put the relationship between wrongdoings and organizational design into the broader scope of social preferences. Social preferences concerning the importance of certain organizational activities may differ across countries. Some countries may be more willing to adopt risky technologies than others, implying a higher probability of failure of those technologies.

The approach of organizational architectures can reflect those social preferences. In a situation when certain products and services are scarce, but the social demand for them is high, a polyarchical organizational design would be preferable because the benefits from a high project approval rate are more socially relevant than the costs of harm inflicted by these activities. Therefore, from a societal perspective one would prefer that firms establish a polyarchical organizational design. Converse-

\footnotetext{
64. Sah \& Stiglitz 1986. The theoretical hypotheses based on this probabilistic approach have found empirical support in the study of decision-making outcomes of mutual funds (Csaczar 2012).

65. Sah \& Stiglitz 1985b, 1986.

66. Baucus \& Near 1991; Simpson, Piquero \& Paternoster 2012, p. 32; Dalton \& Kesner 1988.
} 
Perceived social importance

\begin{tabular}{lll}
\hline Risk of causing harm & High & Low \\
\hline High & (1) Mixed organizational design & (2) Hierarchical organizational design \\
\hline Low & (3) Polyarchical organizational design & (4) Organizational design plays no \\
& & role
\end{tabular}

ly, when certain activities do not play a valuable role in the mindset of society, the prevention of organizational wrongdoing becomes a priority. This aim is attained if firms adopt a hierarchical organizational design.

These findings can further be summarized into the general proposition that, when certain business activities do not play an important (strategic) role for society, the tort law standard of care should enforce a hierarchical organizational design. In contrast, when certain business activities are essential for society, the organizational design standard should be relaxed. For example, to speed up innovation, a polyarchical design is more effective than a hierarchical one. To be more concrete, a pharmaceutical company that produces innovative drugs against such diseases as cancer, Alzheimer and HIV, which are severe plagues of humankind, may implement a decentralized organizational design without being held liable for wrongdoings caused by this architectural choice.

The organizational design perspective provides a theoretical underpinning for the pleas of legal scholars who argue in favour of a 'special' tort law treatment of accidents caused by the operation of innovative industries or innovative firms. For example, Davies and Levine discuss the possibility of abolishing tort liability to a large degree in the "developing and vital biotech industry". ${ }^{67}$ They refer to Burk and Boczar who view biotechnology "as a strategic industry" and "critical to the economic success of the country". 68 The authors compare the role of biotechnology with that of the railroad in the 19th century. To be sure, whether biotechnology is a strategic industry that deserves an exemption from tort liability is a question that cannot be answered scientifically, but what can be said is that a tort law which provides incentives at the organizational design level can better mirror social preferences towards organizational activities and the associated wrongdoing.

One can even go a step further and derive more complex organizational standards applied to different situational contexts. In Table 1, four situations are distinguished.

The variable 'risk of causing harm' (hereafter 'risk') reflects the level of expected harm from a specific activity. The variable 'perceived social importance' refers to the social preference of certain business activities. It reflects the desirability (importance) of a specific business activity for society.

Accordingly the matrix distinguishes four generic scenarios related to different organizational design standards.

Scenario (1): If an activity is associated with high social importance and high risk, then the legal system should enforce a mixed organizational design. In a mixed organizational design hierarchical and decentralized decision-making layers are combined. Sah and Stiglitz call that organizational design "complex organization", 69 while Visser defines it as "hybrid organizational structure". ${ }^{70}$ An 'organizational mix' depends on the relative weight of risk and the associated social preference. If, for example, society weighs the social importance of an activity higher than the associated risk of harm, then a combination of polyarchical and hierarchical subunits is recommended. The polyarchical organizational layer would build the first filter of activities and the hierarchical layer would be placed as the second one (the $P H$ design). That way the relatively stronger preference for social importance can be expressed: the autonomous organizational subunits of the first organizational layer will ensure a high acceptance rate of activities, disregarding to a certain degree the associated risk. But since the expected harm from the approved activities is also high, the second screening is conducted by the hierarchical organizational layer, which provides a more rigorous decision-making and is likely to filter risky activities out. Alternatively, society may weigh the risk of harm of an activity relatively higher than its social importance. In this case a different organizational design has to be chosen. The first organizational layer should be a hierarchy. After the first screening this creates a pool of selected activities with a high proportion of activities of a lowrisk type. At the second organizational layer, the autonomous subunits may approve activities, raising the chance that socially important activities are accepted. Those organizational designs can be denoted as $H P$ designs.

Although mixed organizational designs cannot guarantee the elimination of wrongdoing, the organizational design standards may help to reduce the occurrence of wrongdoing on the one hand, and favour socially beneficial activities on the other. Hence, in a tort's case a court would have to decide whether an organizational design 
consisting of autonomous and hierarchical decisionmaking units adequately corresponds to a combination of high accident risk and high social importance of an activity. The companies that have an inadequate organizational design will bear tort liability for organizational wrongdoing.

Scenario (2): In this case, the perceived social importance of an activity is low, while the risk of inflicting harm is high. Then a tort law standard should predominantly induce risk prevention. This is best attained when a hierarchical organizational design for performing those activities is implemented. In those cases, one may also consider whether a prescription of the organizational design by ex-ante regulation is preferable over the ex-post ruling of tort law.

Scenario (3): In this scenario, the risk of wrongdoing is low, but the perceived social importance of an activity is high. To induce companies to undertake an activity, the appropriate organizational design should allow for autonomous decision-making of organizational subunits. Therefore, a court would be recommended not to hold a company liable for wrongdoing caused by the choice of organizational design. In this way, tort liability will not discourage the implementation of a polyarchical organizational design.

Scenario (4): An organizational activity is neither risky nor socially important. In this case, the problem of achieving a socially desired balance between the level of organizational care and the level of activity has low significance. Correspondingly, organizational standards of care in tort law are not required to play such a big role as in the other three scenarios. This does not mean that organizational wrongdoing becomes less important, but it is sufficient that those standards of care are enforced that address individual behaviour.

It is by no means easy to decide whether an industry is socially important and how risky an activity is. Courts, however, may have the capacity to take into account relevant variables on a case-by-case basis. This is not a new development, but is embedded into the legal practice for a long time. For example, an attempt to support infant industries at the end of the 19th century is showcased in Losee v. Buchanan (1873). In that case, a paper company was not held liable for the harm it caused to the neighbouring property by the explosion of a steam boiler. ${ }^{71}$ In the case, it was stated:

We must have factories, machinery, dams, canals and railroads. They are demanded by the manifold wants of mankind, and lay at the basis of our civilization. If I have any of these upon my lands, and they are not a nuisance and are not so managed as to become such, I am not responsible for any damage they accidentally and unavoidably do my neighbor. He receives his compensation for such damage by the general good, in which he shares, and the right which he has to place the same things upon his lands.
This example shows that social preferences concerning certain organizational activities can possibly be reflected in court decisions, even though the level of discretionary power of a judge may be highly debatable.

\section{Conclusions}

Organizational factors are important causes of wrongdoing. Yet organizational antecedents of wrongdoing are largely ignored in the economic analysis of tort law. The dominant agency approach tries to replicate the analysis of individual incentives on the level of organizations, without the proper acknowledgement of the differences between individuals and organizations.

In this paper, we show that organizational factors, such as organizational culture, design and complexity, play a prominent role, as they often constitute the root causes of organizational wrongdoing. We also emphasize that, in order to better address the role of these factors in the economic analysis of organizational wrongdoing and tort law, it is helpful to apply insights from organizational science. Although the research at the intersection of organizational science and economic analysis of tort law is in its infancy, such interdisciplinary research is very promising. By employing the framework of Sah and Stiglitz ${ }^{72}$ we make a step forward towards advancing the economic analysis of tort law beyond the dominant agency theory framework.

\section{Bibliography}

K.S. Abraham \& P.C. Weiler, "Enterprise Medical Liability and the Evolution of the American Health Care System", Harvard Law Reviem 108, 1994, pp. 381-436.

F. Amtenbrink \& K. Heine, "Regulating Credit Rating Agencies in the European Union. Lessons from Behavioural Science", 2 Dovenschmidt Quarterly 1, 2013, pp. 2-15.

L. Andrews, "Studying Medical Error in SITU: Implications for Malpractice Law and Policy", 54 DePaul Lam Reviem, 2005, pp. 357-392.

J. Arlen, "The Potentially Perverse Effects of Corporate Criminal Liability", 23 Journal of Legal Studies, 1994, pp. 832-867.

J. Arlen \& R. Kraakman, "Controlling Corporate Misconduct: An Analysis of Corporate Liability Regimes", 72 NYU Lam Reviem, 1997, pp. 687-779.

J. Arlen \& W.B. MacLeod, "Beyond Master-Servant: A Critique of Vicarious Liability", in M. Stuart Madden (ed.), Exploring Tort Law. Cambridge, Cambridge University Press, 2005, pp. 111-142.

D. Barboza, "Brokers Say Prudential Approved Trading", N.Y. Times, 8 November 2003, C1.

M.S. Baucus \& J.P. Near, "Can Illegal Corporate Behavior Be Predicted? An Event History Analysis", 34 Academy of Management Fournal 1, 1991, pp. 9-36.

B.D. Baysinger, "Organization Theory and the Criminal Liability of Organizations", 71 Boston University Lam Reviem, 1991, pp. 340-376. 
S. Bonaccio \& R.S. Dalal, "Advice Taking and Decision-Making: An Integrative Literature Review, and Implications for the Organizational Sciences", 101 Organizational Behavior and Human Decision Processes, 2006, pp. 127-151.

D. Brodie, "Enterprise Liability: Justifying Vicarious Liability", 27 Oxford Fournal of Legal Studies, 2007, pp. 493-508.

D.L. Burk \& B. Boczar, "Biotechnology and Tort Liability: A Strategic Industry at Risk', 55 The University of Pittsburgh Lam Reviem, 1994, pp. 791-864.

R.D. Cebul, J.B. Rebitzer, L.J. Taylor \& M. Votruba, "Organizational Fragmentation and Care Quality in the U.S. Health Care System", NBER Working Paper Series, 14212, 2008.

M. Christensen \& T. Knudsen, "Design of Decision-Making Organizations”, 56 Management Science, 2010, pp. 71-89.

M.B. Clinard \& P.C. Yeager, Corporate Crime, New York, Free, 1980.

M.B. Clinard \& P.C. Yeager, Corporate Crime, New Brunswick, NJ, Transaction Publishers, 2006.

S.P. Croley, "Vicarious Liability in Tort: On the Sources and Limits of Employee Reasonableness", 69 Southern California Lam Reviem, 1996, pp. 1705-1738.

F.A. Csaszar, "Organizational Structure as a Determinant of Performance: Evidence from Mutual Funds", 33 Strategic Management Fournal, 2012, pp. 611-632.

D.R. Dalton \& I.F. Kesner, "On the Dynamics of Corporate Size and Illegal Activity: An Empirical Assessment", 7 Fournal of Business Ethics, 1988, pp. 861-870.

J.A. Davies \& L.C. Levine, "Biotechnology's Challenge to the Law of Torts", 32 McGeorge Lam Reviem, 2000, pp. 221-235.

D.A. DeMott, "Organizational Incentives to Care about the Law", 60 Lam and Contemporary Problems 4, 1997, pp. 39-66.

R.A. Epstein, Simple Rules for a Complex World, Cambridge, MA, Harvard University Press, 1995.

"Fatal Washington Metro Crash Shows Need for U.S. Transit Rules, NTSB Says", Bloomberg Nems, 27 July 2010. Available at: $\quad<w w w . b l o o m b e r g . c o m / n e w s / 2010-07-27 /$ fatalwashington-metro-crash-shows-need-for-u-s-transit-rulesntsb-says.html> (last accessed 25 March 2014).

P. Fenn, A. Gray \& N. Rickman, "The Economics of Clinical Negligence Reform in England", 114 The Economic fournal, 2004, pp. 272-292.

H.C. Finney \& H.R. Lesieur, "A Contingency Theory of Organizational Crime", in S.B. Bardach (ed.), Research in the Sociology of Organizations, Greenwich, CT, JAI Press, 1982, pp. 255-299.

D.R. Fischel \& A.O. Sykes, "Corporate Crime", 25 fournal of Legal Studies, 1996, pp. 319-349.

A. Foerschler, Corporate Criminal Intent: Toward a Better Understanding of Corporate Misconduct", 78 California Lam Reviem, 1990, pp. 1287-1311.

C. Ford \& M. Condon, "Introduction to 'New Governance and the Business Organization"”, 33 Lam and Policy, 2011, pp. 449-458.

C. Ford \& D. Hess, "Corporate Monitorships and New Governance Regulation: In Theory, in Practice, and in Context", 33 Law and Policy, 2011, pp. 509-541.

J. Gobert \& A.-M. Pascal, European Developments in Corporate Criminal Liability, New York, NY: Routledge, 2011.

R.D. Gordon, "Fictitious Fraud: Economics and the Presumption of Reliance", 9 International fournal of Lam in Context, 2013, pp. 506-519.

N. Gunningham \& D. Sinclair, "Organizational Trust and the Limits of Management-Based Regulation", 43 Lam and Society Reviem, 2009, pp. 865-900.

B. Heiderhoff \& G. Zmij, Tort Lam in Poland, Germany and Europe, Munich, Sellier European Law Publishers, 2009.

J.A. Henderson, Jr., "Why Negligence Dominates Tort", 50 UCLA Law Reviem, 2002, pp. 377-405.
P.D. Jacobsen \& S.D. Pomfret, "Establishing New Legal Doctrine in Managed Care: A Model of Judicial Response to Industrial Change", 32 University of Michigan Journal of Lam Reform 4, 1999, pp. 813-849.

H.S. James, "Reinforcing Ethical Decision Making through Organizational Structure", 28 Fournal of Business Ethics, 2000, pp. 43-58.

M.C. Jensen \& W.H. Meckling, "Theory of the Firm: Managerial Behavior, Agency Costs, and Ownership Structure", 3 Fournal of Financial Economics, 1976, pp. 305-360.

V.S. Khanna, "Corporate Liability Standards: When Should Corporations be Held Criminally Liable?”, 37 American Criminal Law Reviem, 2000, pp. 1239-1283.

P. Koellinger, M. Minniti \& C. Schade, “'I Think I Can, I Think I Can': Overconfidence and Entrepreneurial Behavior”, 28 Fournal of Economic Psychology, 2007, pp. 502-527.

W.T.H. Koh, "Variable Evaluation Costs and the Design of Fallible Hierarchies and Polyarchies", 38 Economics Letters, 1992, pp. 313-318.

W.T.H. Koh, "Fallibility and Sequential Decision Making", 150 Journal of Institutional and Theoretical Economics 2, 1994, pp. 362-374.

R.H. Kraakman, "Vicarious and Corporate Civil Liability", in M. Faure (ed.), Tort Law and Economics, Cheltenham, Edward Elgar Publishing, 2009, pp. 134-149.

K.D. Krawiec, "Accounting for Greed: Unraveling the 'Rogue Trader' Mystery”, 79 Oregon Lam Reviem, 2000, pp. 301-338.

K.D. Krawiec, "Organizational Misconduct: Beyond the Principal-Agent Model", 32 Florida State University Lam Reviem, 2005, pp. 571-615.

D.C. Langevoort, “Organized Illusions: A Behavioral Theory of Why Corporations Mislead Stock Market Investors (and Cause Other Social Harms)", 146 University of Pennsylvania Law Reviem, 1997, pp. 101-172.

D.C. Langevoort, "Opening the Black Box of 'Corporate Culture' in Law and Economics", 162 Journal of Institutional and Theoretical Economics, 2006, pp. 80-96.

M.S. Mannan, R.A. Mentzer \& J. Zhang, "Framework for Creating a Best-in-Class Safety Culture", 26 Journal of Loss Prevention in the Process Industries, 2013, pp. 1423-1432.

J.G. March \& Z. Shapira, "Managerial Perspectives on Risk and Risk Taking”, 33 Management Science, 1987, pp. 1404-1418.

B. McKelvey, "Quasi-Natural Organization Science", 8 Organization Science, 1997, pp. 352-380.

M. McKendall, B. DeMarr \& C. Jones-Rikkers, "Ethical Compliance Programs and Corporate Illegality: Testing the Assumptions of the Corporate Sentencing Guidelines”, 37 fournal of Business Ethics, 2002, pp. 367-383.

M.A. McKendall \& J.A. Wagner III, "Motive, Opportunity, Choice, and Corporate Illegality", 8 Organization Science 6, 1997 pp. 624-647.

M.M. Mello \& D.M. Studdert, "Deconstructing Negligence: The Role of Individual and System Factors in Causing Medical Injuries", 96 The Georgetomn Lam Journal, 2008, pp. 599-623.

D.A. Moore \& T.G. Kim, "Myopic Social Prediction and the Solo Comparison Effect", 85 Fournal of Personality and Social Psychology, 2003, pp. 1121-1135.

M.J. Nathanson, "Hospital Corporate Negligence: Enforcing the Hospital's Role of Administrator", XXVIII Tort and Insurance Law Fournal 3, 1993, pp. 575-595.

B.K. Payne, White-Collar Crime: The Essentials, Thousand Oaks, CA, Sage, 2013.

C. Perrow, "Normal Accident at Three Miles Island", 18 Society, 1981, pp. 17-26.

C. Perrow, Normal Accidents: Living with High-Risk Technologies, Princeton, NJ, Princeton University Press, 1999. 
P.G. Peters Jr., "Making Hospitals Accountable", 32 Regulation 2, 2009, pp. 30-36.

J.D. Peters \& J.C. Peraino, "Malpractice in Hospitals: Ten Theories for Direct Liability", 12 Lam, Medicine and Health Care, 1984, pp. 254-259.

C. Prendergast, "The Provision of Incentives in Firms", XXXVII Fournal of Economic Literature, 1999, pp. 7-63.

S. Pulver, "Making Sense of Corporate Environmentalism", 20 Organization and Environment 1, 2007, pp. 44-83.

M. Punch, "The Organizational Component of Corporate Crime", in J. Gobert \& A.-M. Pascal (eds.), European Developments in Corporate Criminal Liability, New York, NY, Routledge, 2011, pp. 101-113.

I. Rosenthal, "Major Event Analysis in the Unites States Chemical Industry: Organizational Learning Vs. Liability", in A. Hale, B. Wilpert \& M. Freitag (eds.), After the Event: From Accident to Organizational Learning, New York, NY, Elsevier, 1997, pp. 179-195.

R.K. Sah, "Fallibility in Human Organizations and Political Systems", 5 Journal of Economic Perspectives, 1991, pp. 67-88.

R.K. Sah \& J.E. Stiglitz, "Economics of Committees", Economic Growth Center Discussion paper no. 486. New Haven, CT, Yale University, 1985a. Available at: <http://papers.ssrn. com/sol3 / papers.cfm?abstract_id=2085735\#\#> (last accessed 15 February 2014).

R.K. Sah \& J.E. Stiglitz, "Human Fallibility and Economic Organization", 75 American Economic Reviem, 1985b, pp. 292-297.

R.K. Sah \& J.E. Stiglitz, "The Architecture of Economic Systems", 76 American Economic Reviem 1986, pp. 716-727.

S. Shavell, "Strict Liability Versus Negligence", 9 The Fournal of Legal Studies 1, 1980, pp. 1-25.

S. Shavell, "Liability for Accidents", in A.M. Polinsky \& S. Shavell (eds.), Handbook of Lam and Economics, Vol. 1, Amsterdam, Elsevier, 2007, pp. 139-182.

H. Shefrin \& E.M. Cervellati, "BP's Failure to Debias: Underscoring the Importance of Behavioral Corporate Finance", 1 The Quarterly Fournal of Finance, 2011, pp. 127-168.

H.A. Simon, "Rational Decision-Making in Business Organizations", 69 The American Economic Reviem, 1979, pp. 493-513.

S.S. Simpson, N.L. Piquero \& R. Paternoster, "Rationality and Corporate Offending Decisions", in A.R. Piquero \& S.G. Tibbets (eds.), Rational Choice and Criminal Behavior: Recent Research and Future Challenges, New York, NY, Routledge, 2012, pp. 25-40.

P. Slovic, The Perception of Risk, London, Earthscan, 2000.

N. Stieglitz \& K. Heine, "Innovations and the Role of Complementarities in a Strategic Theory of the Firm", 28 Strategic Management Fournal, 2007, pp. 1-15.

A.L. Stinchcombe, "Social Structure and Organizations", in J.G. March (ed.), Handbook of Organizations, Chicago, IL, Rand McNally, 1965, pp. 142-193.

A.O. Sykes, "The Economics of Vicarious Liability", 93 Yale Law Fournal, 1984, pp. 1231-1280.

A.O. Sykes, "The Boundaries of Vicarious Liability: An Economic Analysis of the Scope of Employment Rule and Related Legal Doctrines", 101 Harvard Lam Reviem 3, 1988, pp. 563-609.

J. Tirole, "Hierarchies and Bureaucracies: On the Role of Collusion in Organizations", II Journal of Law, Economics, and Organization 2, 1986, pp. 181-214.

R.G. Thornton, JD, "Responsibility for the Acts of Others", 23 Baylor University Medical Center Proceedings 3, 2010, pp. 313-315.

D. Vaughan, "Toward Understanding Unlawful Organizational Behavior”, 80 Michigan Law Reviem, 1982, pp. 1377-1402.
D. Vaughan, "The Dark Side of Organizations: Mistake, Misconduct, and Disaster", 25 Annual Reviem of Sociology, 1999, pp. 271-305.

B. Visser, "Complexity, Robustness, and Performance: TradeOffs in Organizational Design", Tinbergen Institute Discussion Paper 2002-048/1, Faculty of Economics, Erasmus University Rotterdam, 2002. Available at: <http://papers.ssrn. $\mathrm{com} / \mathrm{sol} 3 /$ papers.cfm?abstract_id $=316481>$ (last accessed 20 December 2014).

West's Encyclopedia of American Law. Vicarious Liability, Farmington Hills, MI, Gale Group, 2003. Available at: <www. encyclopedia.com/topic/Vicarious_Liability.aspx\#2> (last accessed 21 November 2015).

T. Wu, "Intellectual Property, Innovation, and Decentralized Decisions", 92 Virginia Law Reviem, 2006, pp. 101-127. 